\title{
Flood risk management in the USA: implications of national flood insurance program changes for social justice
}

\author{
David Shively ${ }^{1}$
}

Published online: 9 October 2017

(C) Springer-Verlag GmbH Germany 2017

\begin{abstract}
The National Flood Insurance Program (NFIP), an essential element of US flood management, has been modified by recent legislation to make it financially solvent. Primarily affecting policy types that have long been subsidized, the reconfigured program will result in these being converted to risk-based policies and this has produced concerns over policy affordability, especially for moderate- to lower-income households. The Homeowners Flood Insurance Affordability Act of 2014 does require the program's administrator, the Federal Emergency Management Agency (FEMA), to develop an affordability framework and program to present to the US Congress for enactment. These NFIP changes are considered in the context of its historic challenges and through the lens of risk perception studies and their social justice implications. Studies show that perception of flood risk is conditioned by
\end{abstract}

experience with flooding as much as by economic factors, and coupling of flood risk and climate change in FEMA communications is likely to be counterproductive. More deliberative and collaborative engagement with at-risk communities is important. The NFIP changes might exacerbate social injustice, but less so than a retreat from or dismantling of the program.

This article was originally intended as part of the special issue on the "Social justices in the context of adaptation to climate change - reflecting on different policy approaches to distribute and allocate flood risk management" but was inadvertently published prematurely in Regional Environmental Change Volume 17, Issue 6, pp. 1663-1672, https://doi.org/10.1007/s10113-017-1127-3.
David Shively

david.shively@umontana.edu

1 Department of Geography, University of Montana, 32 Campus Drive, Missoula, MT 59812, USA 